\title{
The Design of Motor Drive for Brushless DC Motor
}

\author{
Tze-Yee Ho \\ Additional information is available at the end of the chapter \\ http://dx.doi.org/10.5772/intechopen.78815
}

\begin{abstract}
The electric machines have been applied to the industrial and commercial areas for several decades. The high performance of control and fast dynamic response of electric machines can be achieved via motor drive because of high development of semiconductors such as the microcontroller and power transistors. Brushless DC motor (BLDC) and permanent magnet $\mathrm{AC}$ synchronous motors drives have many advantages such as high efficiency, small size, less rotor losses, and fast torque response over the induction motor drives. Therefore, this chapter will focus on the design and implementation of a motor drive as well as its realization of control algorithm. At the beginning of chapter, the fundamental of energy conversion for electric machines is introduced. The dynamic model for brushless dc motor is derived and explained in detail in section two. The $120^{\circ}$ conduction and $180^{\circ}$ conduction of switching device for an inverter are also described and illustrated. The control design of a speed-controlled motor drive is described in section three. The hardware and software design of a motor drive based on a microcontroller is given in section four. The experimental results are also presented and discussed. Finally, a conclusion is made in section five.
\end{abstract}

Keywords: brushless DC motor, motor drive, inverter, $120^{\circ}$ conduction

\section{Introduction}

The electrical machine is the bridge of energy conversion between the electrical system and mechanical system, as shown in Figure 1. The electrical machine can be an electric motor. For an electric motor, the input is electrical energy represented by voltage and current, and the output is mechanical energy delivered to the mechanical load, which is represented by speed and torque. On the contrary, the mechanical energy can be converted to electric energy and transferred to electrical system by electrical machine, which is called as electric generator. 


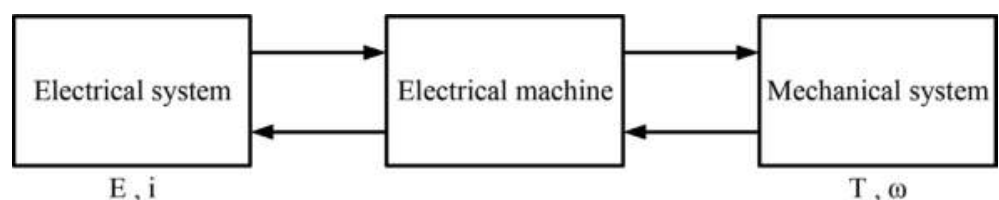

Figure 1. The structure of energy conversion.

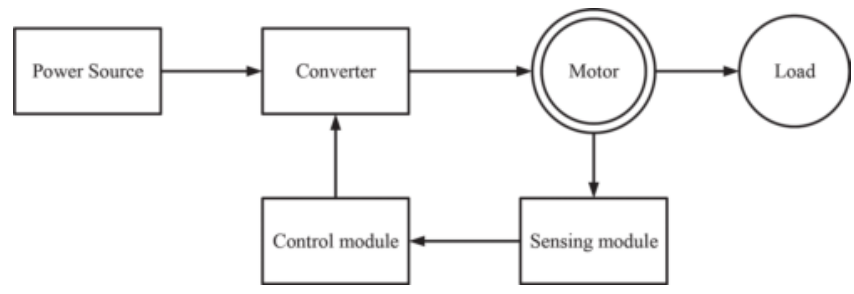

Figure 2. The block diagram of an electrical drive.

A simplified block diagram of an electrical drive is shown in Figure 2. It mainly consists of power source, converter, motor, load, sensing module, and control module. Power source can be supplied by AC line supply or DC battery. Load can be washing machine, range hood, pumps, air conditioners, fans, machine tools, or electric drills. The motor has the characteristics required by the load and the capability to transfer the energy from the source to the load. Most commonly used electrical motors are DC motors, brushless DC motors, induction motors, permanent magnet synchronous motors, stepper motors, and switched reluctance motors. The converter converts the electrical energy of the input source in the form suitable to the motor. Depending on the energy from required by the input power source and motors, AC to DC converters (rectifiers or controlled rectifiers), DC to DC converters (step-up converters or step-down converters), inverters, and cycloconverters are commonly used in the electrical drives design [1, 2]. Sensing module is employed to detect rotor position, rotor speed, motor current, or motor terminal voltages. It is required for the closed-loop control. The control module is the core controller of the overall electrical drive. Due to the high development of power semiconductors, the control module such as microcontrollers, DSPs, ARMs, or FPGA are widely adopted according to the complexity functions for the motor drive requirements.

\subsection{Torque equation}

A motor generally drives a load through some transmission systems as shown in Figure 3. The energy keeps balance, which performs the operation of transmission. Hence, torque developed by motor is counter balanced by a load torque $T_{L}$ and a dynamic torque. The energy transferred from the motor to load is maintained constant. It can be expressed by the following torque equation [3]:

$$
T_{e}=J \frac{d \omega_{m}}{d t}+B \omega_{m}+T_{L}
$$




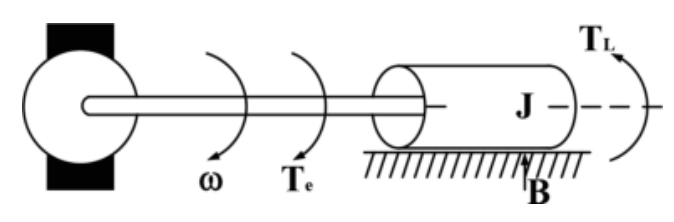

Figure 3. Motor load system.

$\mathrm{T}_{\mathrm{e}}$ is instantaneous value of developed motor torque, $\mathrm{N} \mathrm{m} . \omega_{\mathrm{m}}$ is instantaneous angular velocity of motor shaft, rad/s. J is inertia of motor-load system, $\mathrm{kg} \mathrm{m}^{2}$ and $\mathrm{T}_{\mathrm{L}}$ is the instantaneous value of load torque, $\mathrm{N} \mathrm{m}$.

\subsection{The conduction of switching device}

In recent decade, because of the high developments of power electronics and advanced semiconductor devices, the adjustable speed drive such as brushless DC motor (BLDC) drives, has been well developed and widely employed to the industrial and commercial applications. A typical motor drive consisting of an AC/DC converter, LC DC link, and an inverter is shown in Figure 4. The AC/DC conversion of electric power converts $\mathrm{AC}$ input power source to the $\mathrm{DC}$ link voltage. The DC to AC conversion is known as inverter, which converts the DC power to $\mathrm{AC}$ power required by motor and is normally accomplished by pulse width modulation technique [4]. The inverter may receive DC power from a battery but in most applications it is fed by a rectifier. The switching devices (Q1-Q6) can be BJTs, MOSFETs, IGBTs, GTOs, or thyristors with external commutation circuits and accompanied with six diodes [5].

Assume the inverter feeds a balanced three-phase wye connected resistor load. Two modes of control signals can be applied to the switching transistors: $120^{\circ}$ conduction mode and $180^{\circ}$ conduction mode.

\subsection{1. $120^{\circ}$ conduction mode}

Each switching device is turned on for one-third of a cycle, or $120^{\circ}$. Consequently, only two switching devices can conduct simultaneously at any instant. It is most suitable for a delta connected load because it has a six-step output voltage waveform across any of its phases. The gating signals of each switching device are shown in Figure 5(a) and the corresponding three-phase line voltages are shown in Figure 5(b). The output voltage waveforms of an ideal

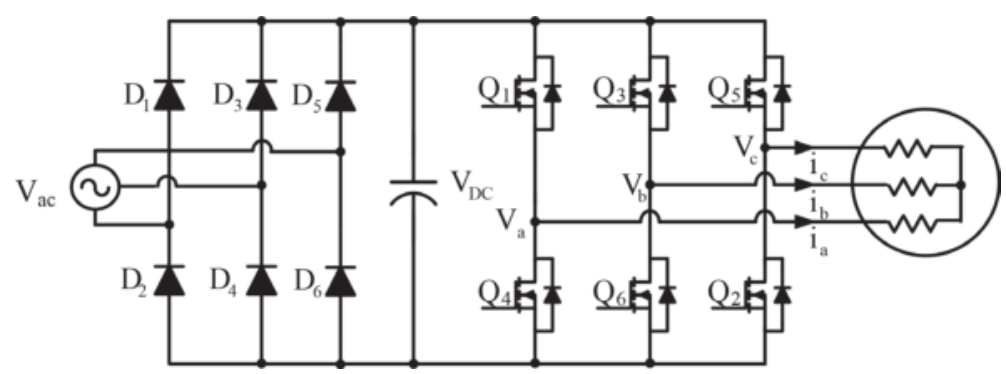

Figure 4. A typical three phase bridge inverter. 


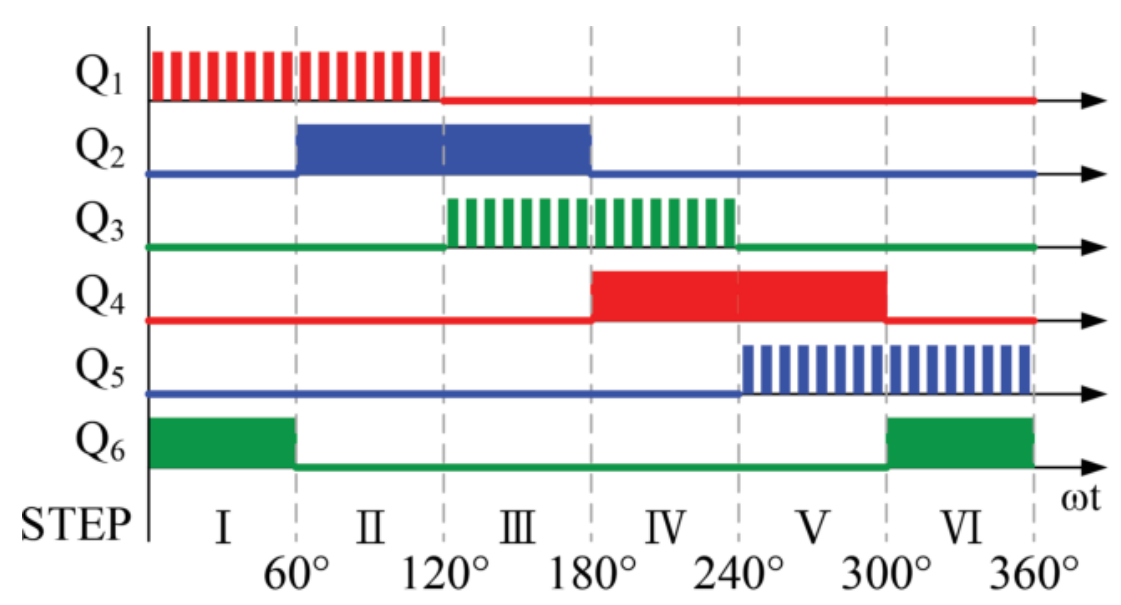

(a)

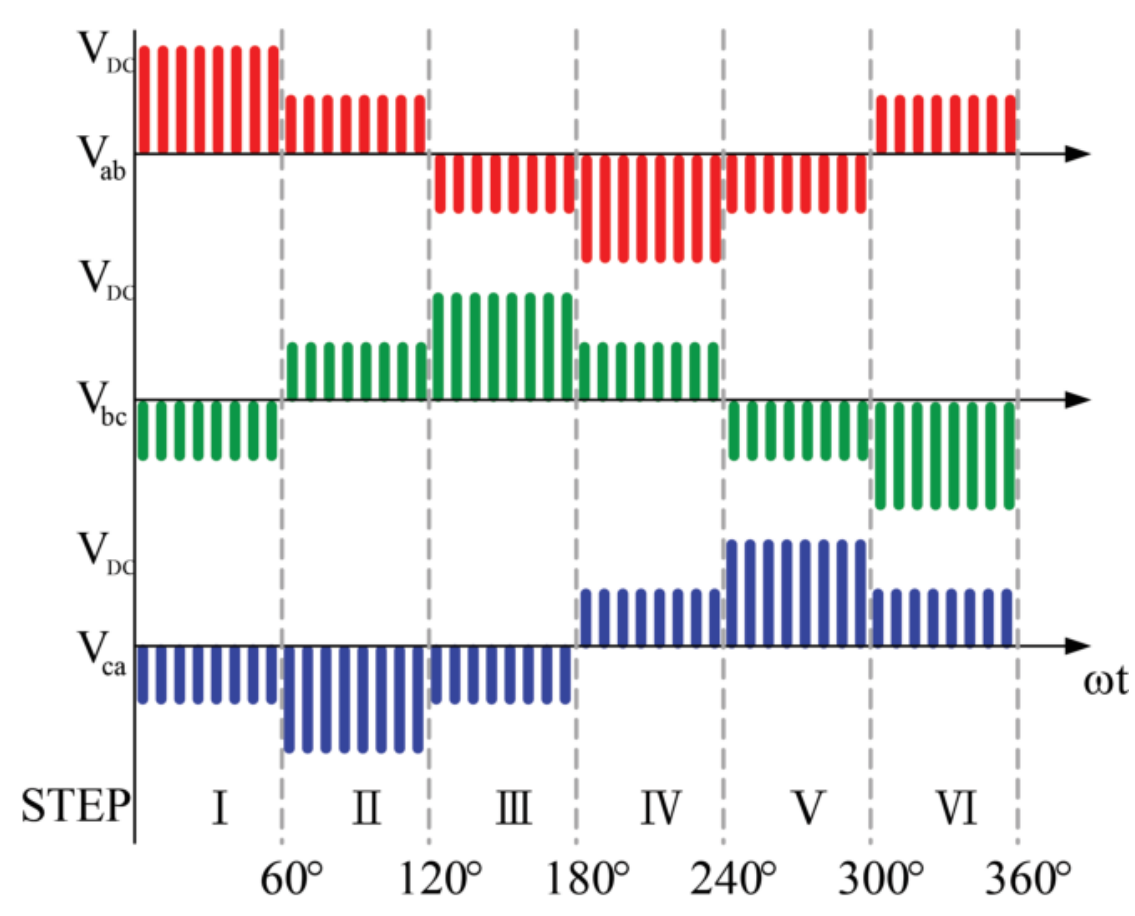

(b)

Figure 5. (a) Gating signals of $120^{\circ}$ conduction mode and (b) the line-to-line voltages for $120^{\circ}$ conduction mode. 


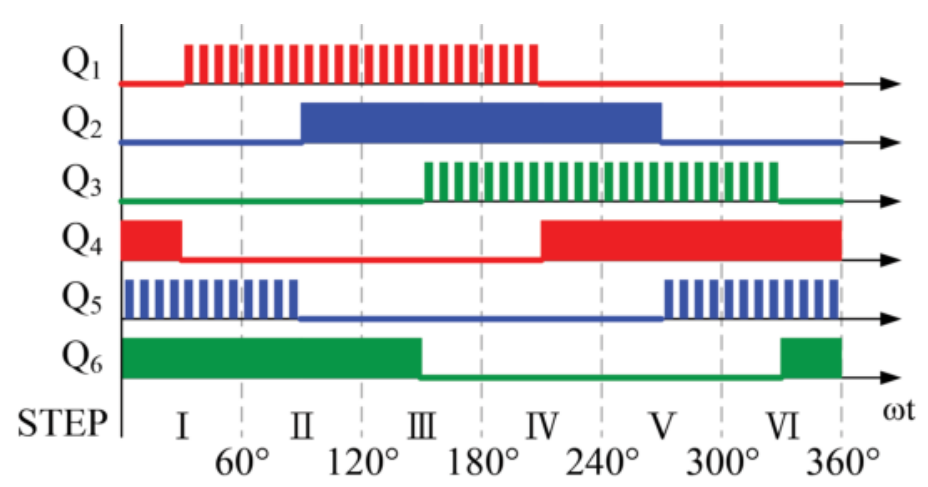

(a)

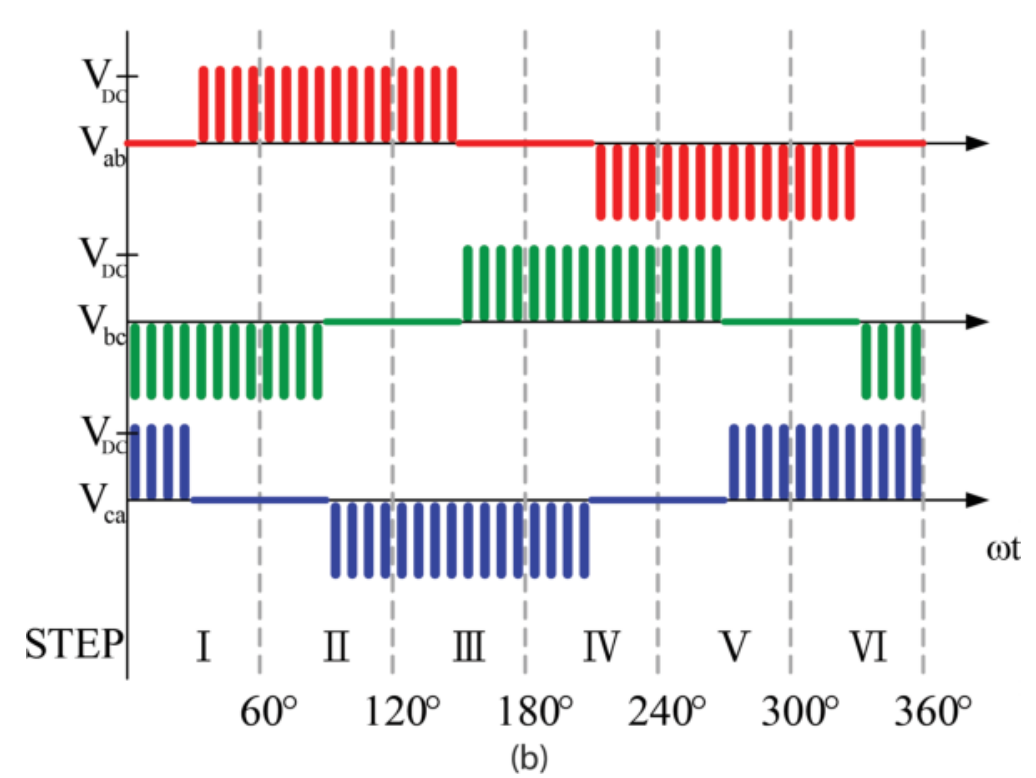

Figure 6. (a) Gating signals of $180^{\circ}$ conduction mode and (b) the line-to-line voltages for $180^{\circ}$ conduction mode.

inverter should be sinusoidal. However, the output voltages are usually square waveform or quasi square waveform. This means that the output voltage inherently contains harmonic contents. The rms value of fundamental phase voltage is $0.39 \mathrm{~V}_{\mathrm{DC}}$ and can be found from the calculation of Fourier series for line voltages [5, 6].

\subsection{2. $180^{\circ}$ conduction mode}

For $180^{\circ}$ conduction mode, each switching device conducts is turned on and off at $180^{\circ}$ interval. At any instant of time, three switching devices always remain turn-on state. The gating signals for 
each switching device are phase displacement of $120^{\circ}$ as shown in Figure 6(a). Consequently, a three-phase output voltage can be obtained with respect to the corresponding switching sequence pattern, as shown in Figure 6(b). The rms value of fundamental phase voltage is $0.45 \mathrm{~V}_{\mathrm{DC}}$. Compared to the $120^{\circ}$ conduction mode, it has much higher output voltage under any operating condition. In other words, it has better voltage utilization of switching devices [5-7].

\section{The dynamic model of a BLDC motor}

The equivalent circuit of a BLDC motor is shown in Figure 7. The stator phase voltage equations $\left(\mathrm{V}_{\mathrm{an}}, \mathrm{V}_{\mathrm{bn}^{\prime}}\right.$ and $\left.\mathrm{V}_{\mathrm{cn}}\right)$ related to the stator phase currents $\left(\mathrm{i}_{\mathrm{a}^{\prime}} \mathrm{i}_{\mathrm{b}^{\prime}}\right.$, and $\left.\mathrm{i}_{\mathrm{c}}\right)$ and back electromotive force $\left(e_{a^{\prime}} e_{b^{\prime}}\right.$ and $\left.e_{c}\right)$ for a BLDC motor, are expressed by $(1)[5,6]$.

$$
\begin{aligned}
& \mathrm{V}_{\mathrm{an}}=\mathrm{R}_{\mathrm{a}} \mathrm{i}_{\mathrm{a}}+\mathrm{L}_{\mathrm{aa}} \frac{\mathrm{di}_{\mathrm{a}}}{\mathrm{dt}}+\mathrm{L}_{\mathrm{ab}} \frac{\mathrm{di}_{\mathrm{b}}}{\mathrm{dt}}+\mathrm{L}_{\mathrm{ac}} \frac{\mathrm{di}_{\mathrm{c}}}{\mathrm{dt}}+\mathrm{c}_{\mathrm{a}} \\
& \mathrm{V}_{\mathrm{bn}}=\mathrm{R}_{\mathrm{b}} \mathrm{i}_{\mathrm{b}}+\mathrm{L}_{\mathrm{ba}} \frac{\mathrm{di}_{\mathrm{a}}}{\mathrm{dt}}+\mathrm{L}_{\mathrm{bb}} \frac{\mathrm{di}_{\mathrm{b}}}{\mathrm{dt}}+\mathrm{L}_{\mathrm{bc}} \frac{\mathrm{di}_{\mathrm{c}}}{\mathrm{dt}}+\mathrm{e}_{\mathrm{b}} \\
& \mathrm{V}_{\mathrm{cn}}=\mathrm{R}_{\mathrm{c}} \mathrm{i}_{\mathrm{c}}+\mathrm{I}_{\mathrm{ca}} \frac{\mathrm{di}_{\mathrm{a}}}{\mathrm{dt}}+\mathrm{I}_{\mathrm{cb}} \frac{\mathrm{di}_{\mathrm{b}}}{\mathrm{dt}}+\mathrm{I}_{\mathrm{cc}} \frac{\mathrm{di}_{\mathrm{c}}}{\mathrm{dt}}+\mathrm{e}_{\mathrm{c}}
\end{aligned}
$$

where $R_{a^{\prime}} R_{b^{\prime}}$ and $R_{c^{\prime}}$ represent the phase resistance for each phase, $L_{a a^{\prime}} L_{b b^{\prime}}$ and $L_{c c}$ represent the self-inductance for each phase, $\mathrm{L}_{\mathrm{ab}}, \mathrm{L}_{\mathrm{bc}}$ and $\mathrm{L}_{\mathrm{ca}}$ represent the mutual inductance between either of two phases, and $e_{a^{\prime}} e_{b^{\prime}}, e_{c^{\prime}}$ represent the back EMF for each phase. If a three-phase balanced system is considered, that is, $i_{a}+i_{b}+i_{c}=0$, the stator voltages in (1) can be rearranged to matrix form as

$$
\left.\begin{array}{c}
-V_{a n} \\
V_{b n} \\
V_{c n}
\end{array}\right]=\left[\begin{array}{ccc}
R_{s} & 0 & 0 \\
0 & R_{s} & 0 \\
0 & 0 & R_{s}
\end{array}\right]\left\lceil\begin{array}{l}
i_{a} \\
i_{b} \\
i_{c}
\end{array}\right]+\frac{d}{d t}\left[\begin{array}{ccc}
L_{s} & 0 & 0 \\
0 & L_{s} & 0 \\
0 & 0 & L_{s}
\end{array}\right]\left[\begin{array}{c}
i_{a} \\
i_{b} \\
i_{c}
\end{array}\right]+\left[\begin{array}{c}
e_{a} \\
e_{b} \\
e_{c}
\end{array}\right]
$$

In steady state, the air gap power in terms of the electromagnetic torque and speed is expressed by

$$
\mathrm{e}_{\mathrm{a}} \mathrm{i}_{\mathrm{a}}+\mathrm{e}_{\mathrm{b}} \mathrm{i}_{\mathrm{b}}+\mathrm{e}_{\mathrm{c}} \mathrm{i}_{\mathrm{c}}=\mathrm{T}_{\mathrm{e}}^{()_{\mathrm{m}}}
$$

The electromagnetic torque is then given by

$$
\mathrm{T}_{\mathrm{e}}=\frac{\mathrm{e}_{\mathrm{a}} \mathrm{i}_{\mathrm{a}}+\mathrm{e}_{\mathrm{b}} \mathrm{i}_{\mathrm{b}}+\mathrm{e}_{\mathrm{c}} \mathrm{i}_{\mathrm{c}}}{\omega_{\mathrm{m}}}
$$

Assume the flux linkage is continuous. The induced emfs are derivatives of the flux linkage. By proper control of the motor, the electromagnetic torque can be expressed by

$$
\mathrm{T}_{\mathrm{c}}=\mathrm{K}_{\mathrm{t}} \mathrm{i}_{\mathrm{a}}
$$

The electromagnetic torque expressed in (6) indicates that it can be controlled by the stator current with the torque constant, $\mathrm{K}_{\mathrm{t}}$. This is very similar to the control of separately DC motor drive. The load model can be expressed in terms of the motor speed, $\omega_{\mathrm{m}^{\prime}}$ a moment of inertia, $\mathrm{J}$, 


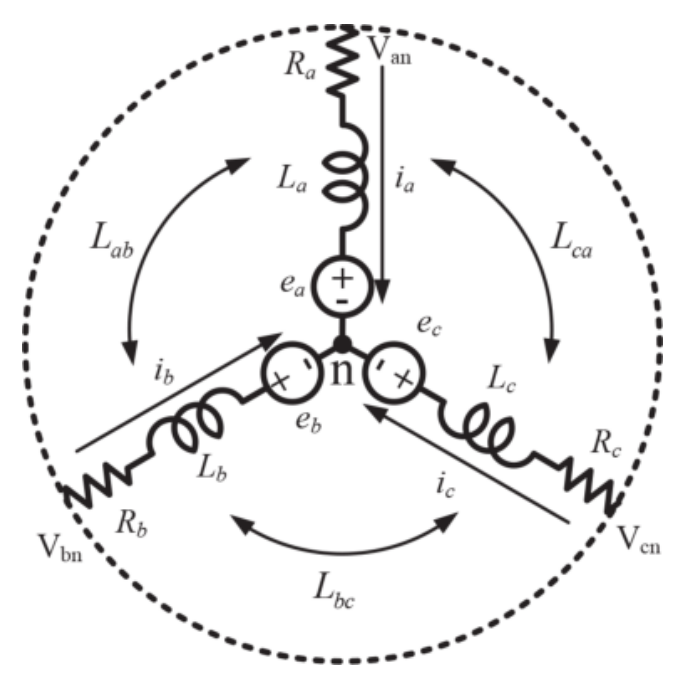

Figure 7. The equivalent circuit of a BLDC motor.

in $\mathrm{kg} \mathrm{m}^{2} / \mathrm{s}^{2}$ with a viscous friction $\mathrm{B}$, in $\mathrm{N} \mathrm{m} / \mathrm{rad} / \mathrm{s}$. The electromagnetic torque, $\mathrm{T}_{\mathrm{e}^{\prime}}$ in $\mathrm{N}$ m then drives the load torque, $\mathrm{T}_{\mathrm{L}^{\prime}}$ in $\mathrm{N} \mathrm{m}$ as represented in (1) and repeated here.

$$
\mathrm{J} \frac{\mathrm{d} \omega_{\mathrm{m}}}{\mathrm{dt}}+\mathrm{B} \omega_{\mathrm{m}}+\mathrm{T}_{\mathrm{L}}=\mathrm{T}_{\mathrm{e}}
$$

\section{The design of a speed controller}

For a speed-controlled motor drive, the time constants of the current loop are usually much smaller than that of the load and the speed controller. In such situation, the control system with simplified current loop for a motor drive is shown in Figure 8. If the 3-dB frequency of current control loop is properly selected, the current controller, $\mathrm{G}_{\mathrm{i}}(\mathrm{s})$ can be approximated to [8].

$$
\mathrm{G}_{\mathrm{i}}(\mathrm{s}) \cong \frac{1}{1+\mathrm{sT}_{\mathrm{c}}}
$$

Assume that $T_{c}$ is very small in the operating frequency interval, $G_{i}(s)$ is approximate to be unity. The PI control is usually employed to the speed controlled motor drive system and has proved to achieve good performance. The transfer function of speed controller, $G_{s}(s)$, can then be expressed by [9].

$$
\mathrm{G}_{\mathrm{s}}(\mathrm{s}) \quad \mathrm{K}_{\mathrm{ps}}+\frac{\mathrm{K}_{\mathrm{is}}}{\mathrm{s}}
$$

where $\mathrm{K}_{\mathrm{ps}}$ is the proportional gain and $\mathrm{K}_{\mathrm{is}}$ is the integrator gain. As we observe the speed control loop, the open-loop transfer function of the speed response has three poles, which can be obtained from the integrator time delay constant, current loop time delay, and the load time constant, respectively. 


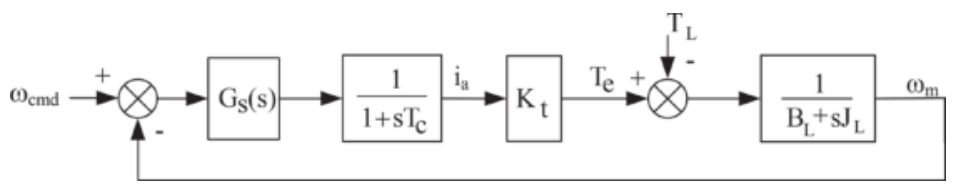

Figure 8. The current loop for motor drive.

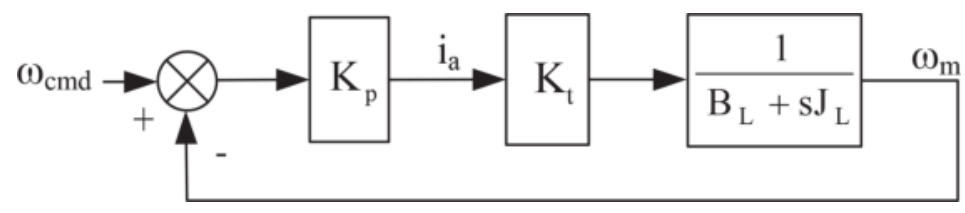

Figure 9. The overall control system of speed-controlled motor drive.

For a speed-controlled drive system, the 3-dB frequency generated from the current loop time delay is always designed to be higher than the rotor frequency. In addition, the 3-dB frequency is obtained from the integrator time delay of PI controller is usually chosen to be smaller than the rotor frequency. From the approximation of current loop crossover frequency and the corner frequency of PI controller, the complete speed-controlled drive system is redrawn in Figure 9. The system is inherently stable since the maximum phase angle of the complete control system is $-90^{\circ}$. Adjusting the proportional gain of speed controller, $\mathrm{K}_{\mathrm{ps}^{\prime}}$ can be applied to meet the requirements of the overshoot for the overall control system $[8,9]$.

\section{The implementation of a BLDC motor drive}

The system structure with control algorithm of motor drive based on a microcontroller is shown in Figure 10. It consists of a microcontroller, protection circuit, optical coupling isolation, inverter, current sensor, Hall effect sensor, and communication interface. For the design and implementation of an electric bicycle, the AC power source and rectifier are replaced by DC battery. The microcontroller dsPIC 30FXX series manufactured by Microchip technology incorporate is the core controller of the electric bicycle. It is a 16-bit CPU with the capability of digital signal processing. Moreover, it supports many powerful modules such as builtin PWM module, addressable encoder interface module, and input capture module; these make the design friendly and thus shorten the development schedule. The three-phase bridge inverter comprises six switching power MOSFETs. The photocoupler is used for electrical isolation between the microcontroller system and bus voltage. The motor currents from the DC bus are sensed through the current detection circuit. The magnet pole and rotor position are detected by the Hall effect sensor. The speed and rotor position can be calculated and precisely controlled, accordingly. The $120^{\circ}$ conduction of pulse width modulation technique for MOSFETs switching, is employed to drive the thee-phase inverter. 


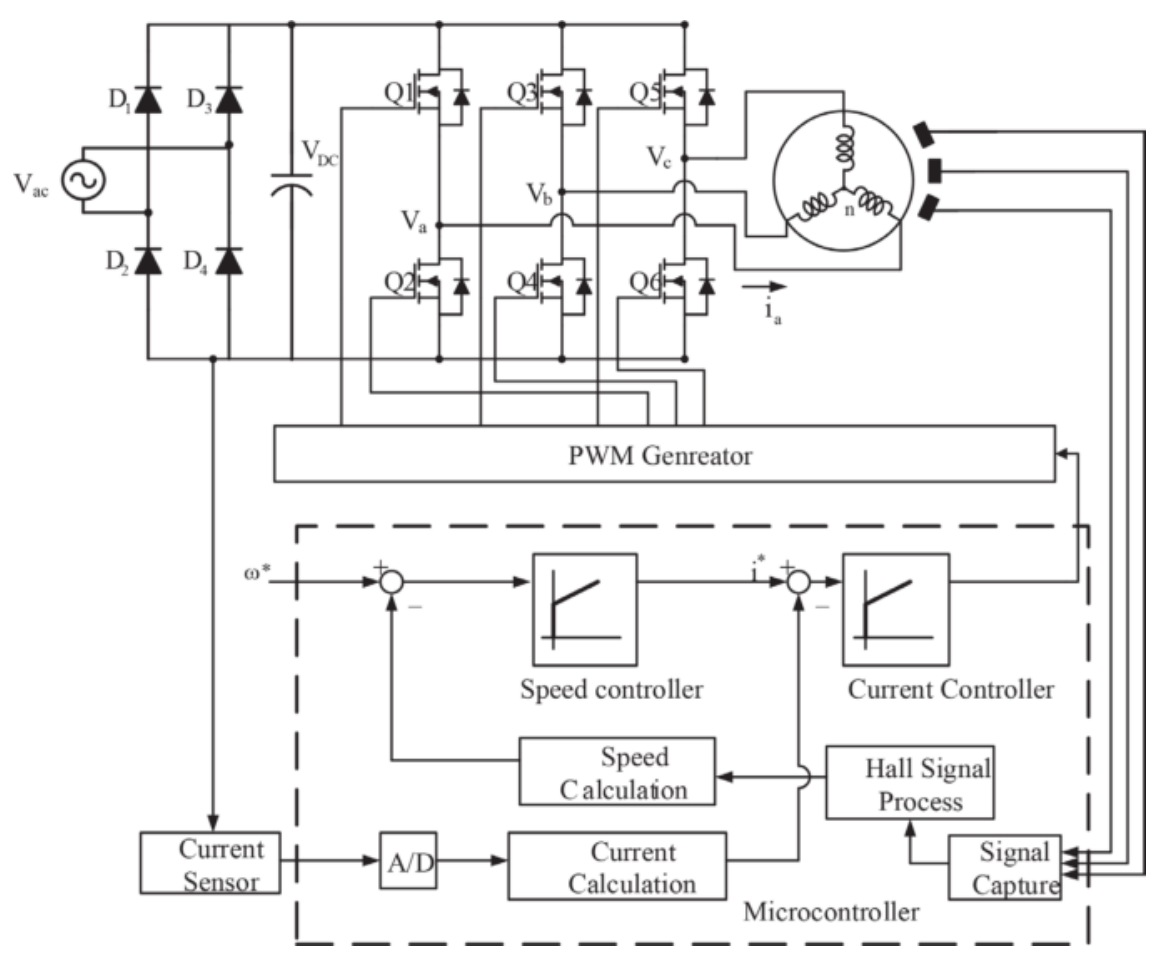

Figure 10. The system structure of a motor drive.

Figure $\mathbf{1 1}$ is the main program of a motor drive for electric bicycle design. The initializations for I/O configuration, Timer 1, Timer 2, ADC, and PWM settings are firstly processed in the main program. Most of the functions for electric bicycle are programmed in the microcontroller firmware, which includes the circuit protection mechanism, PWM generation, motor currents calculation, rotor position and speed calculation, and rotor pole position $[8,10]$.

The speed and currents are usually implemented in the PWM interrupt routine, as shown in Figure 12. The sensing current is firstly calculated and fed to the current controller. Since PWM frequency is $20 \mathrm{kHz}$, the current controller is updated for every $50 \mu \mathrm{s}$. After the calculation of current controller, the speed calculation is then performed by speed controller. The speed is constrained by the limiter in the operating speed range [11].

In order to obtain the proper control of the BLDC motor, the timing between rotor position detected by Hall effect sensor and the corresponding back emf, must always be kept in a fixed sequence. Figure 13 shows the timing sequence between the rotor position (Ch1-Ch3) and the corresponding back emf (Ch4). The motor parameters for the experimental test are $K_{t}=0.0761021 \mathrm{~N} \mathrm{~m} / \mathrm{A}$, $\mathrm{J}_{\mathrm{L}}=0.000245 \mathrm{~kg} \mathrm{~m}^{2}$, and $\mathrm{B}_{\mathrm{L}}=0.00731 \mathrm{~N} \mathrm{~m} \mathrm{~s} / \mathrm{rad}$. The magnitude frequency response of Bode plot with different $K_{p s}$ is shown in Figure 14. Observing the Figure 14, it can be found that the 3-dB rotor frequency is around $800 \mathrm{rad} / \mathrm{s}$. Figure 15 shows the step response of the speed from zero to 


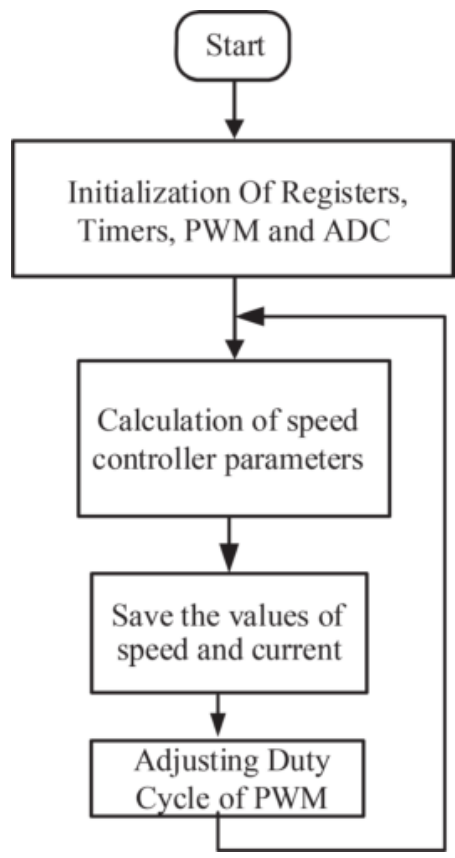

Figure 11. Main program of a motor drive for electric bicycle.

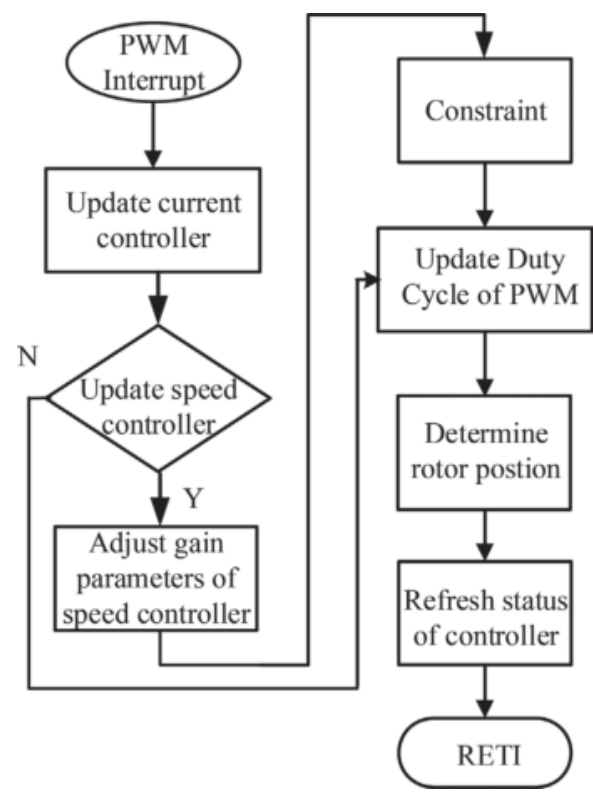

Figure 12. The PWM interrupt routine. 


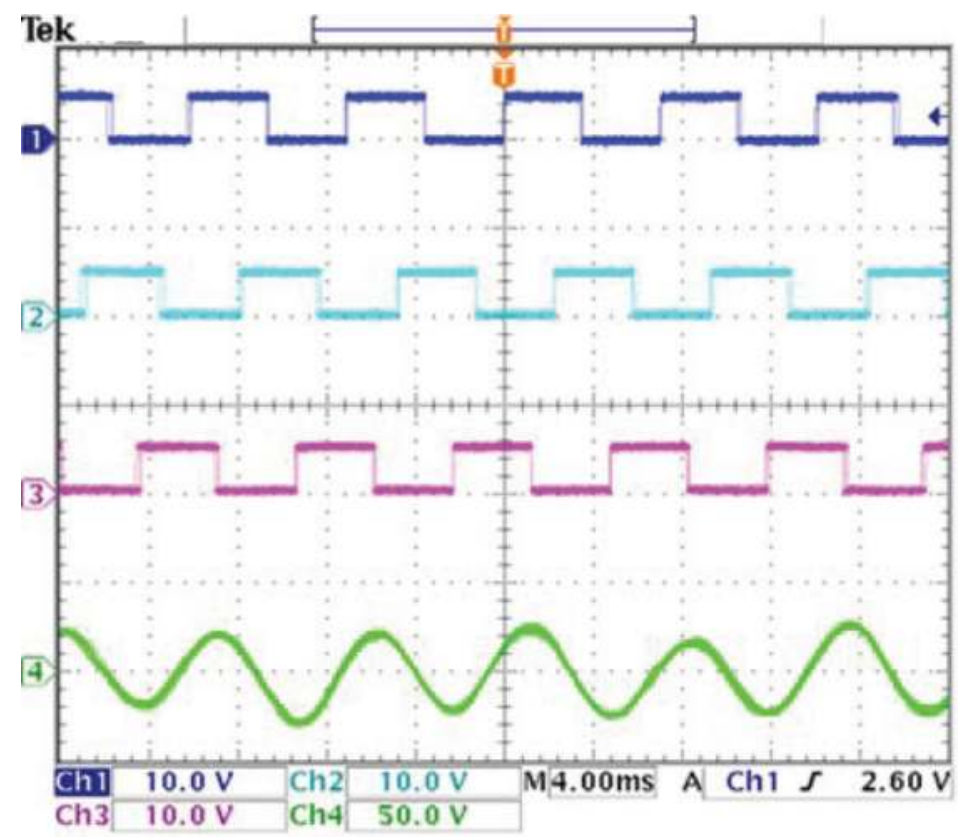

Figure 13. The timing sequence of Hall effect sensing signals and back emf.

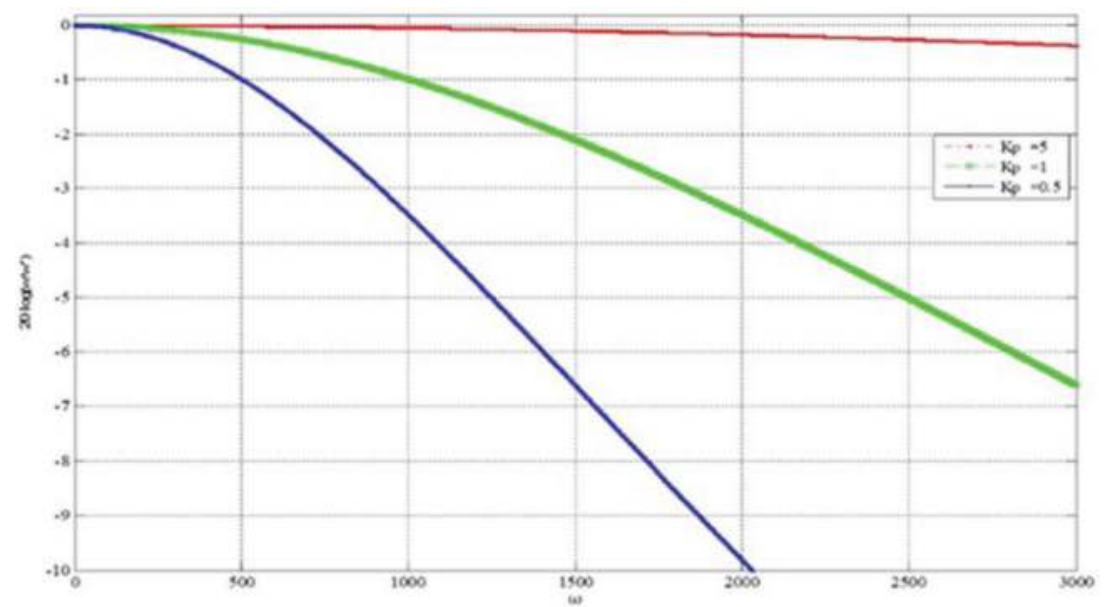

Figure 14. The magnitude response of rotor frequency [8].

$200 \mathrm{rpm}$ under the load of $10 \mathrm{~kg} \mathrm{~cm}$. It can be observed that the motor drive can reach the command speed within the $1.5 \mathrm{~s}$. The phase currents under the load of $10 \mathrm{~kg} \mathrm{~cm}$ is shown in Figure 16, where Ch1, Ch2, and math represent phase currents A, B, and C, respectively. 


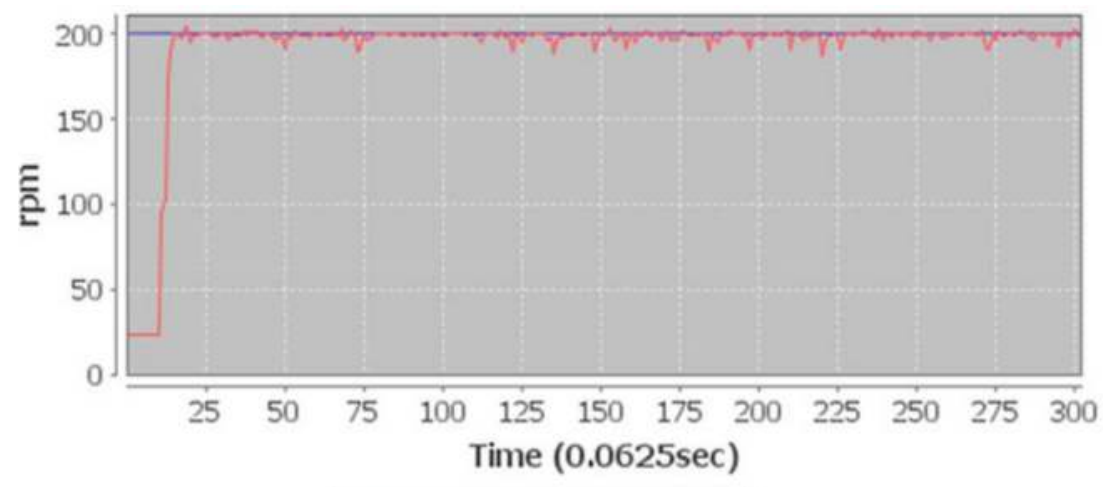

Velocity - Speed Command

Figure 15. The step response of speed under the load of $10 \mathrm{~kg} \mathrm{~cm}$.

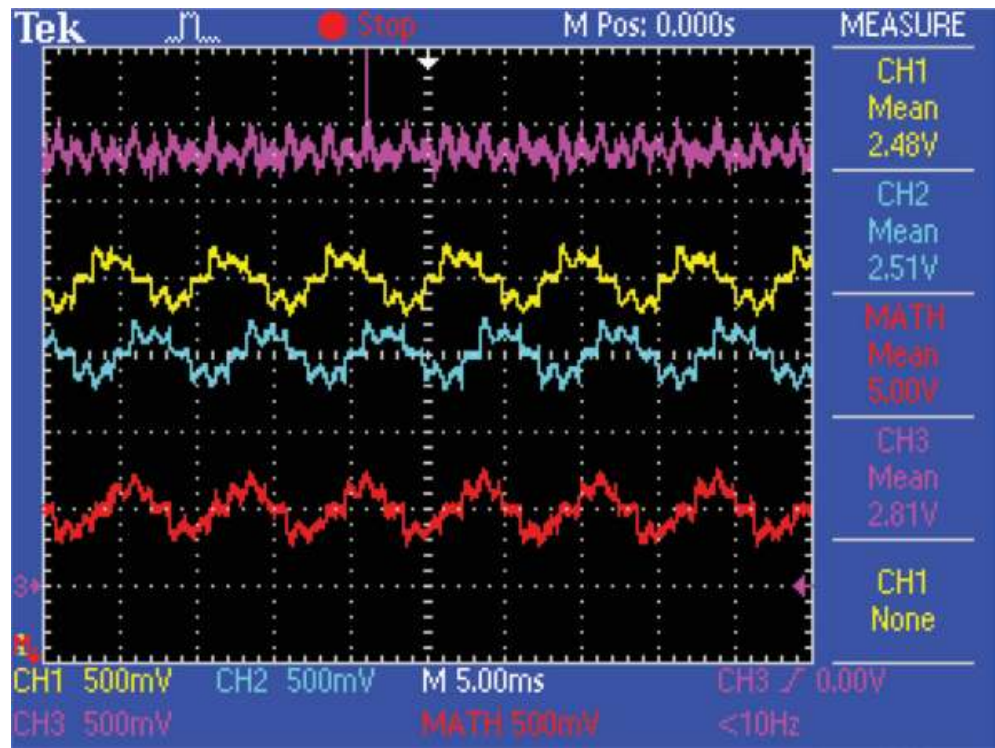

Figure 16. The phase currents under the load of $10 \mathrm{~kg} \mathrm{~cm}$.

\section{Conclusions}

In summary, the speed control of motor drive for an electric bicycle is described in this chapter. The hardware structure including a microcontroller, protection circuit, optical coupling isolation, three-phase inverter, current sensor, and communication interface is well designed. Further, the system software and firmware of microcontroller are programmed and described in detail.

Based on the proposed simple method to find the rotor corner frequency, the range of proportional gain of speed controller can be determined so as to avoid the system oscillation. This result can not 
only speed up the design and implementation of speed controlled motor drive, but also reduce the development time. Further, the contents presented in this chapter about basic knowledge and fundamentals of a motor drive system are suitable for college graduate students. Moreover, I hope it can help engineers and researchers when design and implement a motor drive.

\section{Author details}

Tze-Yee Ho

Address all correspondence to: tyho@mail.fcu.edu.tw

Department of Electrical Engineering, Feng Chia University, Seatwen, Taichung, Taiwan, R.O.C.

\section{References}

[1] Sen PC. Principles of Electric Machines and Power Electronics. New York: John Wiley \& Sons; 1997

[2] Dubey GK. Fundamentals of Electrical Drives. 2nd ed. Kanpur: Alpha Science Int. Ltd.; 2001

[3] Ho Tze-Yee, Chen Yuan-Joan, Chen Po-Hung. The design and implementation of motor drive for foot rehabilitation. Journal of Computers and Electrical Engineering. 2016;56: 795-806

[4] Murphy JMD, Turnbull FG. Power Electronic Control of AC Motors. New York: Pergamon Press; 1988

[5] Rashid MH. Power Electronics: Circuits, Devices, and Applications. 3rd ed. New Jersey: Pearson Education Inc.; 2004

[6] Ahmad M. High Performance AC Drives: Modelling Analysis and Control. Berlin Heidelberg: Springer; 2010

[7] Krishnan R. Electric Motor Drives. New Jersey: Prentice Hall; 2001

[8] Tze-Yee H, Mu-Song C, Wei-Chieh C, Chiang C-H. The design and implementation of motor drive for an electric bicycle. Lectures Notes in Computer Science 7928. Advances in Swarm Intelligence Proceeding Part II. 2013. pp. 488-495

[9] Crnosija P., Krishnan R., Bjazic T. Optimization of PM brushless DC motor drive speed controller using modification of Ziegler-Nichols methods based on Bodé plots. In: IEEE International Power Electronics and Motion Control Conf. 2006. pp 343-348

[10] Krishnan R. Selection criteria for servo motor drives. IEEE Transactions on Industry Applications. 1987;IA-23(2):270-275

[11] Ho T-Y, Mu-Song C, Lung-Hsian Y, Jia-Shen L, Po-Hung C. The design of a high power factor brushless DC motor drive. International Journal of Advancements in Computing Technology. 2012;4(18):P141-P149. ISSN: 2005-8039 
